\title{
Radiation-Triggered Surveillance for UF6 Monitoring
}

\section{December 2015}

Michael Curtis

Pacific Northwest National Laboratory 


\title{
DISCLAIMER
}

This report was prepared as an account of work sponsored by an agency of the United States Government. Neither the United States Government nor any agency thereof, nor Battelle Memorial Institute, nor any of their employees, makes any warranty, express or implied, or assumes any legal liability or responsibility for the accuracy, completeness, or usefulness of any information, apparatus, product, or process disclosed, or represents that its use would not infringe privately owned rights. Reference herein to any specific commercial product, process, or service by trade name, trademark, manufacturer, or otherwise does not necessarily constitute or imply its endorsement, recommendation, or favoring by the United States Government or any agency thereof, or Battelle Memorial Institute. The views and opinions of authors expressed herein do not necessarily state or reflect those of the United States Government or any agency thereof.

\author{
PACIFIC NORTHWEST NATIONAL LABORATORY \\ operated by \\ BATTELLE \\ for the \\ UNITED STATES DEPARTMENT OF ENERGY \\ under Contract DE-AC05-76RL01830
}

Printed in the United States of America
Available to DOE and DOE contractors from the Office of Scientific and Technical Information,
P.O. Box 62, Oak Ridge, TN 37831-0062;
ph: (865) 576-8401
fax: $(865)$ 576-5728
email: reports@adonis.osti.gov

\begin{abstract}
Available to the public from the National Technical Information Service, U.S. Department of Commerce, 5285 Port Royal Rd., Springfield, VA 22161 ph: (800) 553-6847 fax: $(703) 605-6900$ email: orders@ntis.fedworld.gov online ordering: http://www.ntis.gov/ordering.htm
\end{abstract}

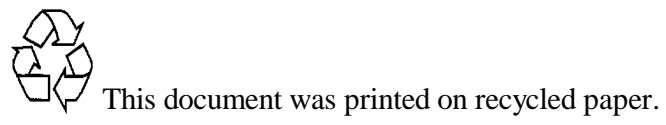




\section{Radiation-Triggered Surveillance for UF6 Monitoring}

\section{Michael Curtis}

Pacific Northwest National Laboratory

December 2015

Prepared for

U.S. Department of Energy

under Contract DE-AC05-76RL01830

Pacific Northwest National Laboratory

Richland, Washington 99352 



\section{Acknowledgments}

Funding for the preparation of this document was provided by the U.S. Department of Energy National Nuclear Security Administration Office of Nonproliferation and International Security in support of the National Nuclear Security Administration Next Generation Safeguards Initiative. Pacific Northwest National Laboratory wishes to thank the Next Generation Safeguards Initiative for their input, support, and guidance in preparing this document. 



\section{Executive Summary}

The International Atomic Energy Agency (IAEA) has begun using surveillance cameras in the feed and withdrawal areas of gas centrifuge enrichment plants (GCEPs), but this application is hampered by the fact that the IAEA's surveillance cameras are nearly always triggered by motion. This generates thousands of review files over the course of a month resulting in an extended review process for inspectors.

The author recommends the use of surveillance in the process area to mitigate the threat of undeclared throughput. Undeclared throughput, referred to as. excess production by the IAEA, is an instance where undeclared feed in the form of natural uranium hexafluoride $\left(\mathrm{UF}_{6}\right)$ is used to produce undeclared product (low-enriched $\mathrm{UF}_{6}$ ). The IAEA currently uses short-notice inspections and short-term operator reporting in the form of mailbox declarations to mitigate the threat of excess production, but these provisions are no substitute for continuous surveillance. ${ }^{\mathrm{a}}$

The IAEA's "New Model Safeguards Approach" recommends the use of surveillance in the process area and/or sealing of all empty and full cylinders as two means of detecting excess production. The problem with a heavy dependence on seals is that frequent attachments and detachments require a continuous onsite presence, something enrichment facilities lack. Surveillance requires significantly less inspector effort and is unobtrusive to operations, but it has its own singularity. Virtually all IAEA surveillance installations are in normally unoccupied areas of facilities, because nearly all are triggered by motion. Motion detection works well in storage vaults and reactor containments, but its use in heavily occupied areas generates a plethora of image files.

This paper recommends the use of radiation detectors, singly or in sets, to trigger surveillance cameras. Ideally, the cameras will monitor cylinders transiting the process area as well as the process area itself. The general process area will be surveyed to record how many cylinders have been attached and detached to the process between inspections. Rad-triggered cameras can dramatically reduce the quantity of recorded images, because the movement of personnel and equipment not involving $\mathrm{UF}_{6}$ cylinders will not generate a surveillance review file.

Operator mailbox declarations will still be required, because the quantities of uranium added or removed from cylinders cannot be determined by surveillance alone, nor can cylinder attachment and detachment to the process be determined with certainty. However, surveillance will certainly mitigate the number of short-notice inspections performed in a year, as one of the principal activities during such inspections is verifying the number of cylinders in the process area.

There have been a number of previous applications of radiation detectors used in conjunction with surveillance, but there are few examples of such systems in open literature, as they are typically installed at high-security fuel cycle facilities, and their environment can seldom be described. In the examples delineated in this report, radiation detectors and surveillance cameras are usually independent, and there is no evidence of a rad-triggered surveillance system that has been employed at a GCEP.

Portal monitors at international border crossings are not analogous to the GCEP-focused concept under consideration, which is detection of a single compound, $\mathrm{UF}_{6}$, solely for the purpose of triggering a stream of surveillance imagery. Portal monitors are designed to detect radiation sources of unknown mass and

a. Short-term operator declarations are submitted in (what are termed) mailboxes. A mailbox refers to a secure, computer database or network in which operators input cylinder-related information in near real-time. The information is time-stamped and unalterable, providing inspectors with a short-term record of cylinder status or movement. Declared information may include the date and time, cylinder number, location, uranium and ${ }^{235} \mathrm{U}$ mass, tare weight, and category designation. 
isotopic composition. In the case of radiation-triggered surveillance at a GCEP, the isotope is known and the mass is unimportant, because the surveillance system is not designed to monitor material but rather the cylinders that contain it. 


\section{Acronyms and Abbreviations}

AP

AMAGB

CAVIS

CoK

DCM-14

EOSS

$\mathrm{F}$

GCEP

IAEA

INFCIRC/153

INFCIRC/540

KMP

MMCT

MWe

$\mathrm{Na}$

NGSS

NPT

NWS

$\mathrm{Pa}$

PCAS

PFPF

PHWR

$\mathrm{Pu}$

RPM

RSAC

SSAC

$\mathrm{U}$

$\mathrm{UF}_{6}$

${ }^{235} \mathrm{U}$

${ }^{238} \mathrm{U},{ }^{234} \mathrm{U}$
Additional Protocol (see also INFCIRC/540)

Advanced Material Accountancy Glovebox

Continuous Automated Vault Inventory System

continuity of knowledge

Digital Camera Module 14 (predecessor to NGSS)

Electronic Optical Sealing System

chemical symbol for fluorine

gas centrifuge enrichment plant

International Atomic Energy Agency

IAEA model comprehensive safeguards agreement

IAEA model Additional Protocol

key measurement point (flow or inventory)

Mobile Monitoring System for Container Transport

Megawatts electric

chemical symbol for sodium

Next Generation Surveillance System

Treaty on the Non-Proliferation of Nuclear Weapons

Nuclear Weapon State

Protactinium

Plutonium Canister Assay System

Plutonium Fuel Production Facility

pressurized heavy water reactor

chemical symbol for plutonium

radiation portal monitor

Regional System of Accounting and Control

State System of Accounting and Control

chemical symbol for uranium

uranium hexafluoride

natural uranium fissile isotope

natural uranium non-fissile isotopes 


\section{Table of Contents}

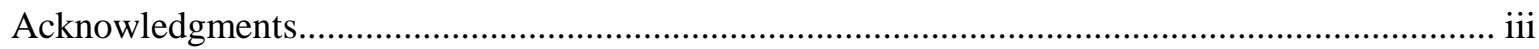

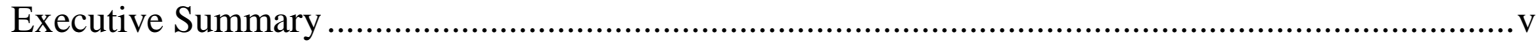

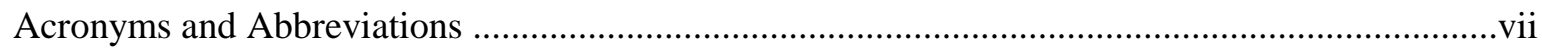

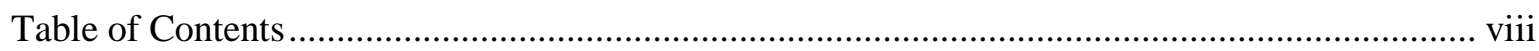

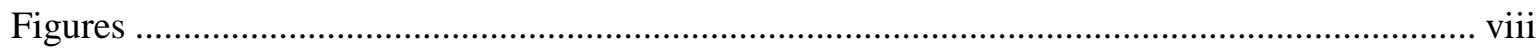

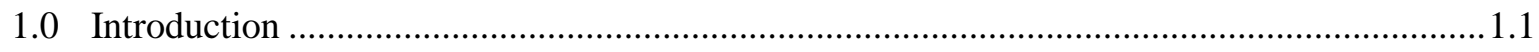

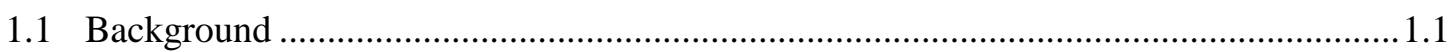

1.2 Surveillance in the Process Area of a GCEP ..................................................................... 1.1

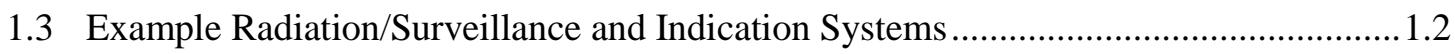

2.0 Rad-Triggered Surveillance in GCEP Process Area ….......................................................2.4

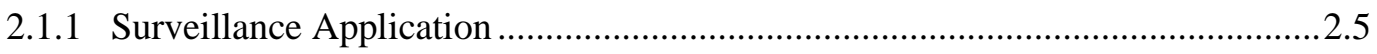

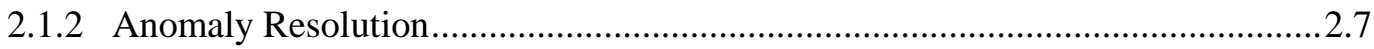

2.2 Process Area Surveillance - Operator/Inspector Advantages ......................................... 2.7

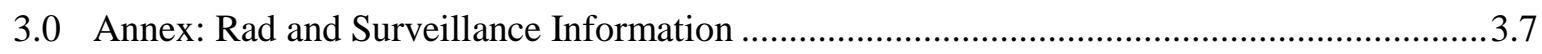

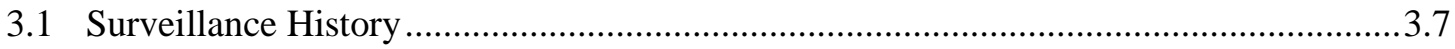

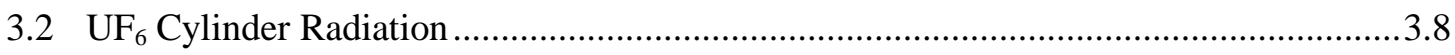

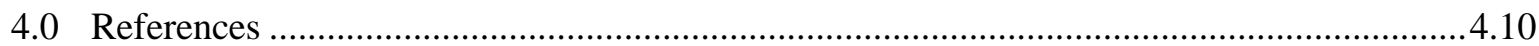

\section{Figures}

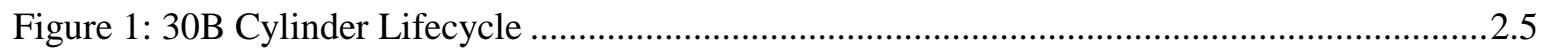

Figure 2: Prospective Camera Placement (overhead view) ....................................................... 2.6

Figure 3: Gamma Dose Rate from 48Y UF 6 cylinder .............................................................. 3.8 


\subsection{Introduction}

\subsection{Background}

The Hexapartite Safeguards Project (HSP) finalized a paper entitled, Inspection Activities Associated with Limited-Frequency Unannounced Access Model Applied to Gas Centrifuge Type Enrichment Plants. It was approved by all GCEP technology-holding participants in $1983 .{ }^{1}$ The HSP is the mechanism that permits IAEA inspectors to perform Limited Frequency Unannounced Access (LFUA) inspections at enrichment plants. An LFUA inspection allows inspectors access to cascade halls on very short notice. The inspectors are constrained to an assigned path and must be accompanied in their walkthrough by plant personnel. The HSP represents a compromise between technology protection and detection of undeclared activities.

Some surveillance/verification items the HSP collaboration ended up not providing include:

- Measurement of uranium hexafluoride $\left(\mathrm{UF}_{6}\right)$ flow inside cascades and associated piping

- Monitoring of the cascade perimeter as a closed boundary. (Although extensively debated, containment and surveillance of the cascade boundary were deemed unnecessary in light of LFUAs.)

- Clear provisions for detecting excess production. (The HSP concluded that in plants with a capacity of less than 2,000 t SWU/a, accountancy and verification of declared items outside the cascade halls, together with LFUA inspections inside, provided a sufficient deterrent to this threat. However, some new facilities far exceed the 2,000 t SWU/a capacity.)

From a gross defect $t^{b}$ perspective, the most intractable diversion scenario involves the introduction of undeclared feed cylinders to an enrichment plant for the purpose of producing undeclared product, capable of being further enriched at a declared or clandestine enrichment facility. The IAEA refers to such undeclared throughput as excess production. When an operator passes an undeclared cylinder and its attendant material through a cascade, the activity can be disguised by matching the throughput of feed, product, and tails in inventory change reports to only what is declared to the IAEA from normal processing. ${ }^{\mathrm{c}}$

Excess production is not explicitly covered by the HSP. It represents a long-standing quandary that cannot be resolved by verifying $100 \%$ of declared cylinders, unless inspectors can establish with certainty there is no undeclared throughput. The IAEA currently addresses this problem by combining short-notice inspections and frequent walkthroughs with frequent operator declarations of cylinder movements in the form of mailbox declarations. Short-notice inspections and walkthroughs may be entirely random (shortnotice random inspection-SNRI) or triggered by various events. Although short-notice inspections can mitigate the threat of excess production, they are performed too infrequently to substitute for continuous monitoring.

\subsection{Surveillance in the Process Area of a GCEP}

In March 2015 the IAEA stated it had been using seals and surveillance in the feed and withdrawal area of the Natanz facility in Iran. ${ }^{2}$ Surveillance is also used to a limited extent at the Resende facility in Brazil. ${ }^{3}$ The use of either containment or surveillance in the process area is requisite for detecting some instances of excess production; however containment has its limitations. Containment in the form of seals is adequate for freezing cylinder content prior to shipment or sampling, but using it to secure emplaced cylinders is problematic, because detaching seals from the doors of a feed or take-off station requires an

b A gross defect represents the loss of a cylinder or all its content.

c If the plant is very large or the excess production quantity is small relative to throughput, the missing material can be diverted into material unaccounted for. 
onsite inspector presence so as not to delay operator activities. ${ }^{\mathrm{d}}$ By contrast, the servicing of surveillance systems does not require operator participation except perhaps as an escort when servicing the cameras or using the review station. ${ }^{\mathrm{e}, \mathrm{f}}$

The use of surveillance in the process area of GCEPs has been an IAEA objective since issuance of the New Model Safeguards Approach in 2006. ${ }^{4}$ Besides mitigating the threat of excess production, surveillance can provide additional information, including: enumerating cylinders, identifying cylinders, recording process attachments and detachments, monitoring unattended verification systems for tampering, maintaining continuity-of-knowledge on previously verified cylinders, and mailbox verification. Notwithstanding, cameras have limitations of their own. They are installed at fixed locations, they must be powered, they require continuous lighting (typically outside inspector control), and their field of view can be altered by contact with equipment or entirely blocked by operator activities. These shortcomings are applicable to camera usage in any application, but nearly all IAEA installations are in normally unoccupied areas, because IAEA camera systems are nearly always triggered by motion.

Motion detection works best in normally unoccupied areas, like storage vaults or reactor containments. The IAEA's current Next Generation Surveillance System (NGSS), like its Digital Camera Module 14 (DCM-14) predecessor, can be triggered by fixed time intervals, various digital inputs, electronic seals, or motion-generated scene changes. In the case of motion triggering, inspectors who service the system designate regions of interest (ROIs) within the field of view. Any scene change within an ROI generates a review file of pre-and-post triggered images.

Regardless of how carefully ROIs are chosen, they can be saturated by the movement of personnel or equipment other than cylinders. This can result in a lengthy review session for inspectors and their corresponding State or Regional System of Accounting and Control (SSAC/RSAC) representatives, because the passage of persons or equipment items other than cylinders will result in the generation of too many changed images in time-lapse mode and too many image files in motion-triggered mode. Filtering out all non-safeguards-related imagery to limit review time is a very difficult task to perform. While software-based solutions such as the Joint Research Centre-Ispra's VideoZoom (still under development) helps inspectors reduce the dataset size by filtering out many of the safeguards-relevant images, PNNL believes a better solution is to limit the number of images at the source. Limiting the number of images only to those involving cylinder movements requires another trigger coincident with, or independent of, motion. Radiation offers one possibility, load-cell or cylinder-saddle-plate activated switches, metal detectors, or crane/cart movement are others.

The advantage of using radiation is that it is passive, easy to apply, and specific to a $\mathrm{UF}_{6}$ cylinder, which is the item of interest. If the detectors are properly placed, the number of nuisance files can be minimized.

\subsection{Example Radiation/Surveillance and Indication Systems}

Most non-contamination-related radiation detectors are linked to security or safety systems. They are designed to alert personnel to the presence of area or airborne radiation above a certain threshold. Frequently, such systems check for radiation sources of unknown quantity and isotopic composition. The radiation portal monitors (RPMs) operated on behalf of U.S. Customs and Border Protection at U.S. ports of entry, are a class of detectors that monitor any radiation emissions from sources of unknown isotopic

d. Operator applied seals, like those of the Electronic Sealing Optical System (EOSS) can be used, but such seals are best applied under surveillance.

e Brazil's Resende GCEP is an exception. At Resende, there is a limited application of surveillance inside the cascade halls, and VACOSS seals are used on disconnected cylinders in the process area (see reference "Safeguards at the Commercial Centrifuge Plant at Resende, Brazil").

f Surveillance cannot be used in the cascade area of an enrichment facility without permission, because it represents a commercially sensitive process step (INFCIRC/153 paragraph 46b.iv). The feed and withdrawal areas are not subject to this circumscription. 
composition and quantity. These monitors are intended to detect plutonium, enriched uranium, other special nuclear material, and sources that could be used in a radiological dispersion device. These materials all produce gamma signatures, and some, a neutron signature as well; however, naturally occurring and man-made radioactive sources, especially medical isotopes, are also detected, resulting in frequent nuisance alarms.

Border-crossing portal monitors are not analogous to GCEP-applied rad-triggered surveillance, which is intended only for detecting a single compound $\left(\mathrm{UF}_{6}\right)$ for the purpose of triggering a stream of surveillance imagery. This paper is concerned only with radiation detectors intended for triggering surveillance. There are few examples of such applications in open literature, because such systems are installed in highsecurity fuel cycle facilities, and the application environment can seldom be described with any specificity in journal articles or conference proceedings. Among the examples below, only two expressly state that surveillance is triggered by radiation. The others may be time-lapse or motion triggered.

\section{Unattended Fuel Flow Monitor (UFFM)}

The UFFM was installed in the High Temperature Engineering Test Reactor at the Japan Atomic Energy Research Institute. ${ }^{5}$ It employs pairs of neutron and $\gamma$ detectors to monitor the movement of fresh mixed-oxide fuel (MOX) assemblies between the core and fuel storage pool. The combination of neutron and $\gamma$ ray signatures characterizes the transferred material as fresh fuel, spent fuel, or some other material. The transfer route is complemented by surveillance, and in at least one application, an underwater camera records fuel element serial numbers. ${ }^{6,7}$ The system was later incorporated into the Modular Integrated Monitoring System, a comprehensive set of networked remote monitoring equipment.

\section{Mobile Monitoring System for Container Transport (MMCT)}

The MMCT maintains continuity of knowledge $(\mathrm{CoK})$ on spent fuel containers transferred by rail. It consists of a GPS locator, a DCM-14 video surveillance module, six ${ }^{3} \mathrm{He}$ neutron detectors, and two ionization chambers. The system was designed to provide CoK for fuel transfers from the Chernobyl Nuclear Power Plant to the Chernobyl Interim Dry Storage facility. ${ }^{8}$ The surveillance portion of the system was designed to capture images during loading and unloading of spent fuel assemblies into a TK-8 flask. Cameras were set to record imagery at a fixed interval of 10 minutes, once per minute when there was a significant change in radiation counts (up or down), and whenever the railcar door opened. ${ }^{9}$ Seals were not considered acceptable for use on TK8 containers because they would require a continual inspector presence.

\section{Continuous Automated Vault Inventory System (CAVIS)}

CAVIS was designed in the mid-1990s to monitor the real-time mass, gamma, and neutron energy of each HEU item in modular storage vaults at $\mathrm{Y}-12 .{ }^{10}$ The development goal was to minimize the labor and radiation exposure attending periodic inventories.

A number of unattended NDA monitoring systems were first installed in the automated Plutonium Fuel Production Facility (PFPF) in Japan. Two are described below:

\section{Advanced Material Accountancy Glovebox (AMAGB)}

The AMAGB was developed to measure the plutonium content of powder and pellets at Japan's PFPF. The PFPF is a MOX fuel production facility that adopted remote and automated fuel fabrication systems to reduce personnel exposure and improve productivity. The AMAGB system measures powder and pellet samples positioned on load cells inside gloveboxes. Neutron coincidence counters derive ${ }^{240} \mathrm{Pu}$ mass, and a high-purity germanium detector and multi-channel analyzer provide plutonium isotopics. When operated in unattended mode, the MAGB computer sends a trigger signal to a camera, creating a timestamped video ID record. ${ }^{11}$ 


\section{The Plutonium Canister Assay System (PCAS)}

The PCAS was designed to measure the plutonium content in PFPF transport canisters, and to verify the transfer of canisters from the storage to the process area. There are up to four cans of MOX material in each canister. The system uses neutron coincidence to estimate the spontaneous fission rate. When this information is combined with declared isotopic ratios, plutonium mass can be determined. ${ }^{\mathrm{g}, 12}$ A camera records the canister ID during the process.

\subsection{Rad-Triggered Surveillance in GCEP Process Area}

The IAEA's new model safeguards approach recognizes the need for the application of surveillance in the process (feed and withdrawal) area of a GCEP, but there are problems to overcome.

The first problem is operator resistance. Objective 2 of the IAEA's New Model Safeguards Approach states that possible safeguards measures to detect the production of undeclared product from undeclared feed requires "surveillance of the feed and withdrawal stations and sealing of the full and empty feed, product and tails cylinders" Added to this proffered safeguards measure is the statement, "...this may be onerous for the operator and the Agency in large plants." ${ }^{13}$ Sealing of all full and empty cylinders would require a full-time inspector presence to secure and break seals without imposing on operator time. ${ }^{\mathrm{h}}$ Surveillance, unlike seals, does not interfere with operator activities, but operators may object to its use in heavily occupied areas, as it would reveal all operator activities in the vicinity. Remote transmission of imagery may be especially difficult to establish; instead the imagery will probably be reviewed onsite.

The second problem related to surveillance in the process area is how best to trigger surveillance cameras in an area of continuous activity. Movement of personnel and equipment in the process area precludes the use of motion detection for triggering surveillance, forcing the use of an alternate trigger. Equipment items such as autoclave doors or saddle contact switches can be used to trigger surveillance cameras, but such triggers neglect the movement of cylinders in-and-out of the area. Radiation detectors, used alone or in combination with motion detectors, have the potential to track cylinders in the process area and while transiting in-and-out.

Surveillance is intended only for monitoring cylinders within the dotted line in Figure 1 -representing the process area and its vicinity. The radiation detectors can be simple GM-tubes, because they are intended only for detecting $\mathrm{UF}_{6}$ in high background areas for the purpose of triggering surveillance. Estimating the deposited gamma energy or isotope identification is unnecessary as there is only one compound present $\left(\mathrm{UF}_{6}\right)$, and its isotopic composition is of no consequence to a system intended only for monitoring cylinder movements. New or recently refurbished product or tails cylinders (non-radioactive ones) will not trigger detectors on entering the process area, but this deficiency is not crucial, because they will trigger surveillance when exiting. All cylinder movements will be recorded by one area camera that will be set to time-lapse mode. Discrepancies between the number of cylinders entering and leaving the area can be resolved in the time-honored method of examining frames from this camera at high speed.

g An improved Plutonium Canister Assay System designed to detect gross and partial defects in the declared plutonium content of plutonium and MOX storage canisters was designed for the MOX fuel fabrication facility in Rokkasho, Japan. It includes an associated gamma isotopics system (GIS) to confirm facility-declared isotopics.

$\mathrm{h}$ Inspector-applied seals have traditionally been employed for $\mathrm{UF}_{6}$ cylinder applications. Host-applied or auto-applied seals of the VACOSS or EOSS variety or other remove-and-replace seals are an option; however, based on the method of application, their verification is difficult to determine. 


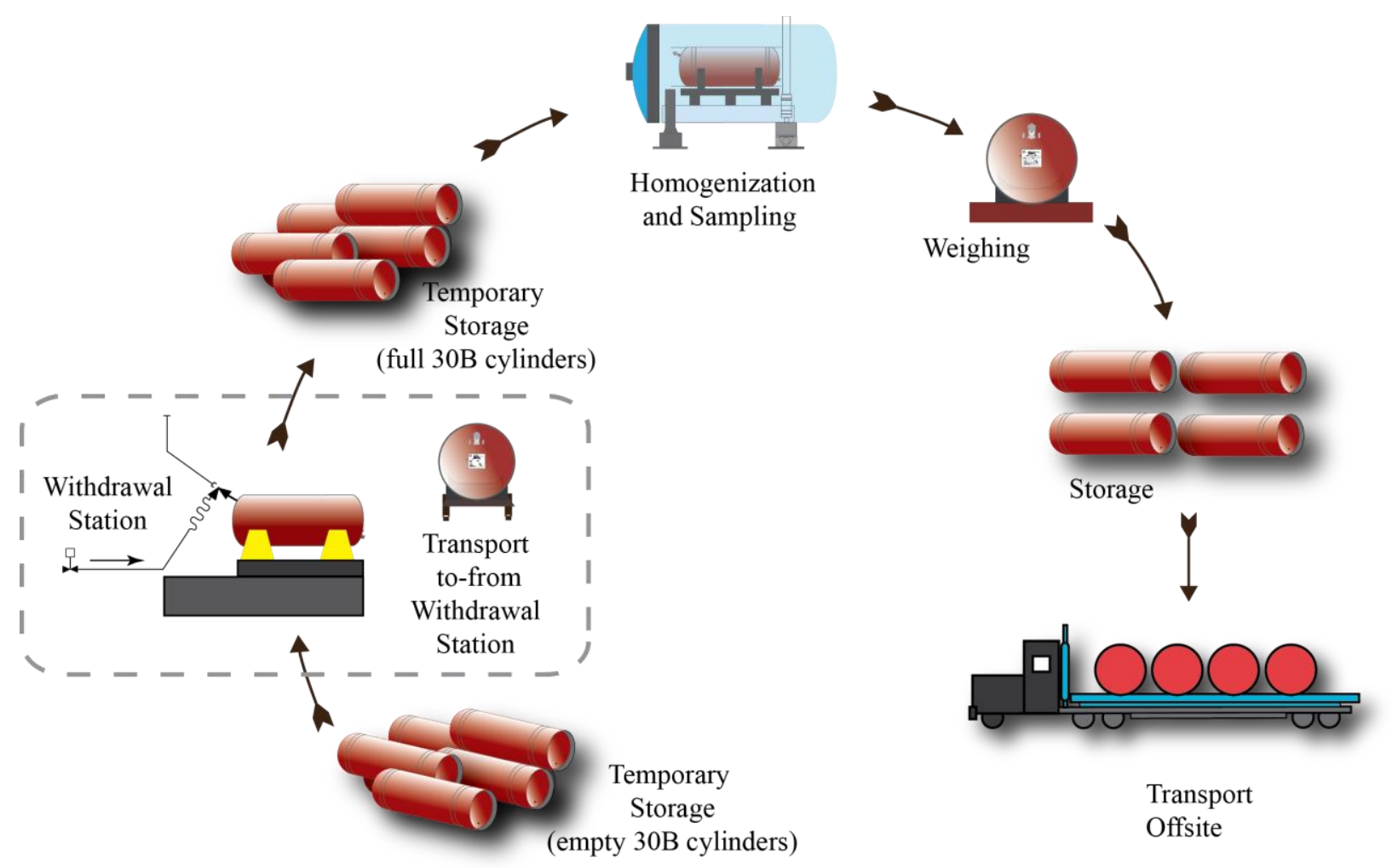

Figure 1: 30B Cylinder Lifecycle

\subsubsection{Surveillance and Rad-Detector Application}

A process area surveillance system may include monitoring of cylinder flow and, if in the vicinity of the process area: the accountancy scale, assay verification station, process stations, sampling stations and blending stations. Two independent equipment trains consisting of cameras with overlapping fields of view, separate cabling, and independent power supplies are required to provide assurance that the loss or blockage of one train will not result in an inconclusive surveillance result. ${ }^{i}$ The frame rate must be sufficient to ensure all potential movements will be captured. This will require observing each of the various operations performed in the vicinity of the process area to determine the required image frequency.

All cameras must be positioned so they will not be vulnerable to glare, jarring, or blockage due to the movement of personnel or portable equipment. Signal amplification and signal logic must be established. An NGSS camera does not AND signals together; consequently, this will require an external circuit to accommodate MOTION AND RADIATION, or a possibly a review station software modification.

Cylinders should be monitored while entering and leaving the process area, and motion-monitoring cameras should be triggered by radiation or radiation and motion. Radiation detectors should be placed to maximize the signal from the cylinder movement path. Shielding and collimation may be required to

i. However, even this arrangement is vulnerable to common mode failures such as a loss of lighting or a sustained loss of power. 
minimize radiation from cylinders placed elsewhere in the vicinity, especially those that are not in fixed stations.

In addition to triggering surveillance, the radiation detectors monitoring the flowpath can also count cylinders as they pass in a manner similar to fuel counters in CANDU reactors. In this case the signals will be fed to a data acquisition module for time-stamped recording.

Radiation triggering setpoints may require periodic modification as a result of a significant change in background radiation. Background radiation intensity is a result of the number of cylinders at feed and withdrawal stations or resting on the floor in non-saddle positions (see Figure 2). ${ }^{\mathrm{j}}$ Background readings for detectors can be periodically adjusted following a period of stability of sufficient duration to ensure there is no cylinder motion in the vicinity of the detector. A significant rise in level from this new background level will generate a surveillance trigger. An algorithm must be devised to modify the triggering setpoints so they are not buried in saturation during periods of high background. An iteration program modeled on a particular site can be used to determine the expected maximum and minimum levels of background resulting from a random distribution of cylinders in various locations.

Radiation detector signals do not require encryption, while authentication can be accomplished with the use of tamper indicating enclosures and conduits.

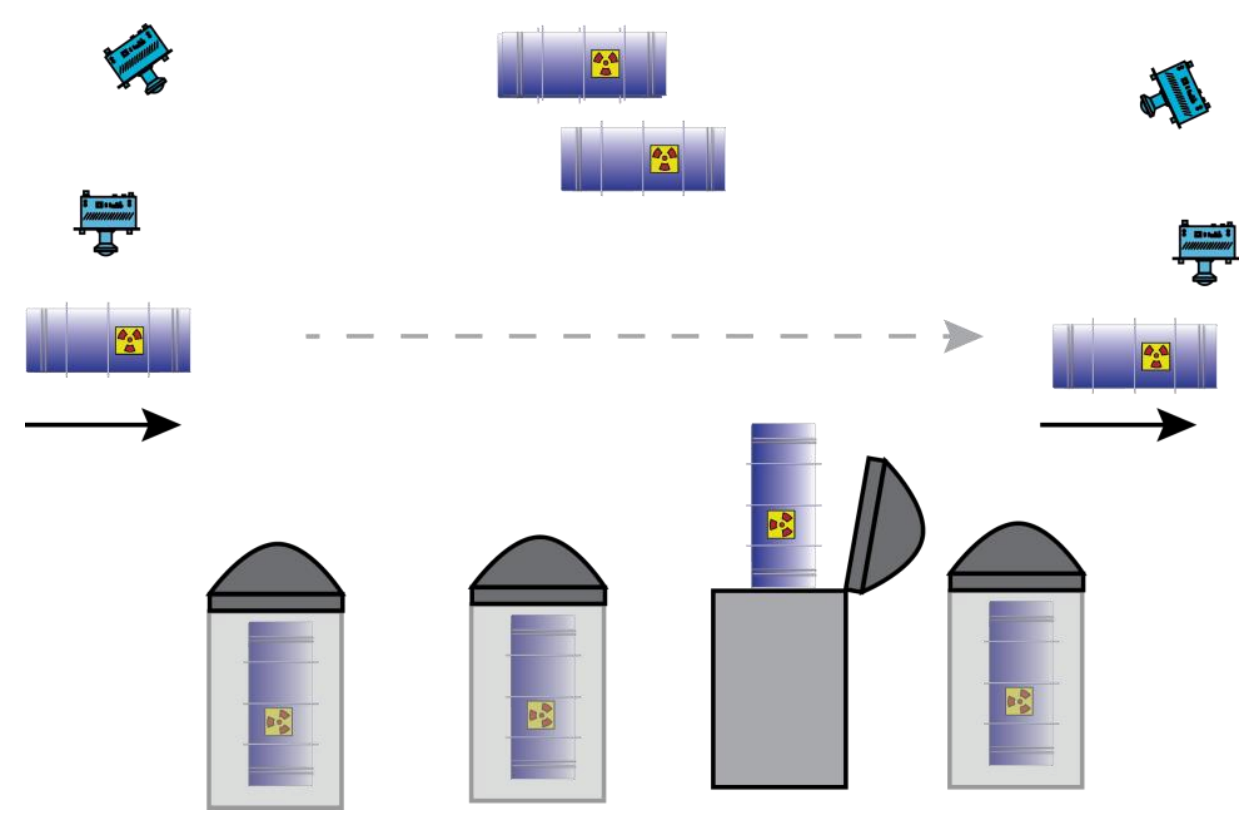

Figure 2: Prospective Camera Placement (overhead view)

\section{Process Area Monitoring}

Two wide-angle-area-monitoring cameras should cover the process area as whole. Process-area cameras will take images at fixed time intervals and will not be triggered by radiation. One camera may be triggered by the opening or closing of a process-station door, but at least one should record imagery at

j. In the case of radiation portal monitors (RPMs), changes in background levels are typically due to environmental factors, while in the case of a GCEP process area, background variations will primarily result from other cylinders in the vicinity of the cylinder(s) in motion. 
fixed intervals. The time-interval camera can be used to resolve operator-inspector disputes in regard to specific incidents.

\subsubsection{Anomaly Resolution}

Potential anomalies will be indicated by discrepancies between Inventory Change Reports and the IAEA's surveillance record. If the date of the discrepancy cannot be discerned from a standard review of the video and radiation record, it will require an exhaustive review of the entire interval. There should be at least one camera with no trigger other than its internal timer that can be used to clarify when the problem occurred. Timed images can also be used in the event one or more radiation detectors fail, generating an inconclusive result from the flow KMP cameras.

\subsection{Process Area Surveillance-Operator/Inspector Advantages}

The cameras will record:

- how many cylinders are in the process area

- when each cylinder enters and leaves

- which process or sampling station currently contains a cylinder and when it entered

Additional cameras and ancillary software might be used to perform cylinder identification, perhaps in conjunction with an unattended, cylinder verification station. In this case, the mass and assay of each cylinder could be verified as well as its entrance and exit from the process area.

From an inspectors' standpoint, monitoring flow in the process area as well as unattended identification, weighing, and assaying of cylinders would virtually eliminate the possibility of excess production, but the use of surveillance by itself is still very valuable. It would prevent the operator from admitting undeclared cylinders to the process in the inspectors' absence. All cylinder passage will have been recorded, and all cylinders on the operator's flowsheet will be eligible for random sampling during the next routine inspection.

From an operator's standpoint, there will assuredly be fewer inspections, and fewer verification activities, especially during LFUAs, as there will be a record of cylinder throughput at the process KMP.

\subsection{Annex: Rad and Surveillance Information}

\subsection{Surveillance History}

The IAEA has utilized unattended surveillance for decades. Until the late 1980s typical Agency surveillance systems employed twin-mounted Minolta movie cameras in one sealed casing. Since the cameras were battery-powered, this arrangement represented $100 \%$ redundancy in the power supply, although the field of view was virtually identical. Each camera took a snapshot at the same set interval, but since they were serviced at different times, the images differed slightly. As there was no means of isolating safeguards-relevant imagery, inspectors had to review each frame at high speed. Reviews could take a half hour or more for each station, and there may have been nearly a dozen units employed at a single KMP. Once film supplies grew short and camera parts difficult to acquire, the IAEA began transitioning to various videotape systems. By the early 1990s, the proliferation of film and tape-based systems: STAR, GEMINI, MUX, COSMOS, ELMO, MIVS, and twin Minoltas, to name a few, resulted in too many for technicians to service. The impetus to develop a digital system stemmed from the desire to minimize the number of systems inspectors and technicians had to be familiar with, reduce the number of spare parts in inventories, and develop a more flexible and reliable system. 
The digital surveillance era began in the mid-1990s when the Digital Camera Module 14 (DCM-14) video family (DSOS ALIP ALIS DMOS) began to be fielded, albeit with significant image compression due to the limited capacity of hard drives. The DCM-14 has been the IAEA's workhorse camera system for nearly two decades, but it is currently being replaced by the IAEA's Next Generation Surveillance System (NGSS), developed by the German Support Program.

The NGSS records imagery at intervals of one second or more. It can also accommodate numerous auxiliary triggers generated by motion, limit switches, doors, load cells, radiation, etc. Triggers not only activate the cameras but, depending on the resolution, cause them to record the incident imagery along with 8-128 pre-trigger images retrieved from a ring buffer. The NGSS review software has been designed to function similarly to the IAEA's Gemini Advanced Review Station. Pixel changes within inspectorassigned regions of interest are used to indicate motion.

\subsection{UF $_{6}$ Cylinder Radiation}

There are several sources of radiation from uranium hexafluoride.

- $\gamma$ photons from decay of ${ }^{238} \mathrm{U}$ and its immediate daughters ${ }^{234} \mathrm{Th},{ }^{234} \mathrm{~Pa}$, and ${ }^{234} \mathrm{~Pa}^{\mathrm{m}}$

- $\quad \gamma$ photons from decay of ${ }^{235} \mathrm{U}$ and its daughter ${ }^{231} \mathrm{Th}$ (only significant in enriched uranium)

- Bremsstrahlung photons from $\beta$ decay of ${ }^{234} \mathrm{~Pa}^{\mathrm{m}}$

- Neutrons from spontaneous fission of ${ }^{238} \mathrm{U}$

- Neutrons from ${ }^{19} \mathrm{~F}(\alpha, \eta)^{22}$ Na reactions

The $185.72 \mathrm{keV}$-line from the decay of ${ }^{235} \mathrm{U}$ has the most influence on the effective dose rate because it has high energy and high photon yield. Decay of ${ }^{238} \mathrm{U}$ gives a daughter nuclide ${ }^{234} \mathrm{Th}$. ${ }^{234} \mathrm{Th}$ has a half-life of 24.1 days, decaying to ${ }^{234} \mathrm{~Pa}$ and ${ }^{234} \mathrm{~Pa}^{\mathrm{m}}$, which both quickly decay to ${ }^{234} \mathrm{U}$. ${ }^{234} \mathrm{Th},{ }^{234} \mathrm{~Pa}$, and ${ }^{234} \mathrm{~Pa}^{\mathrm{m}}$, are in secular equilibrium after about 150 days.

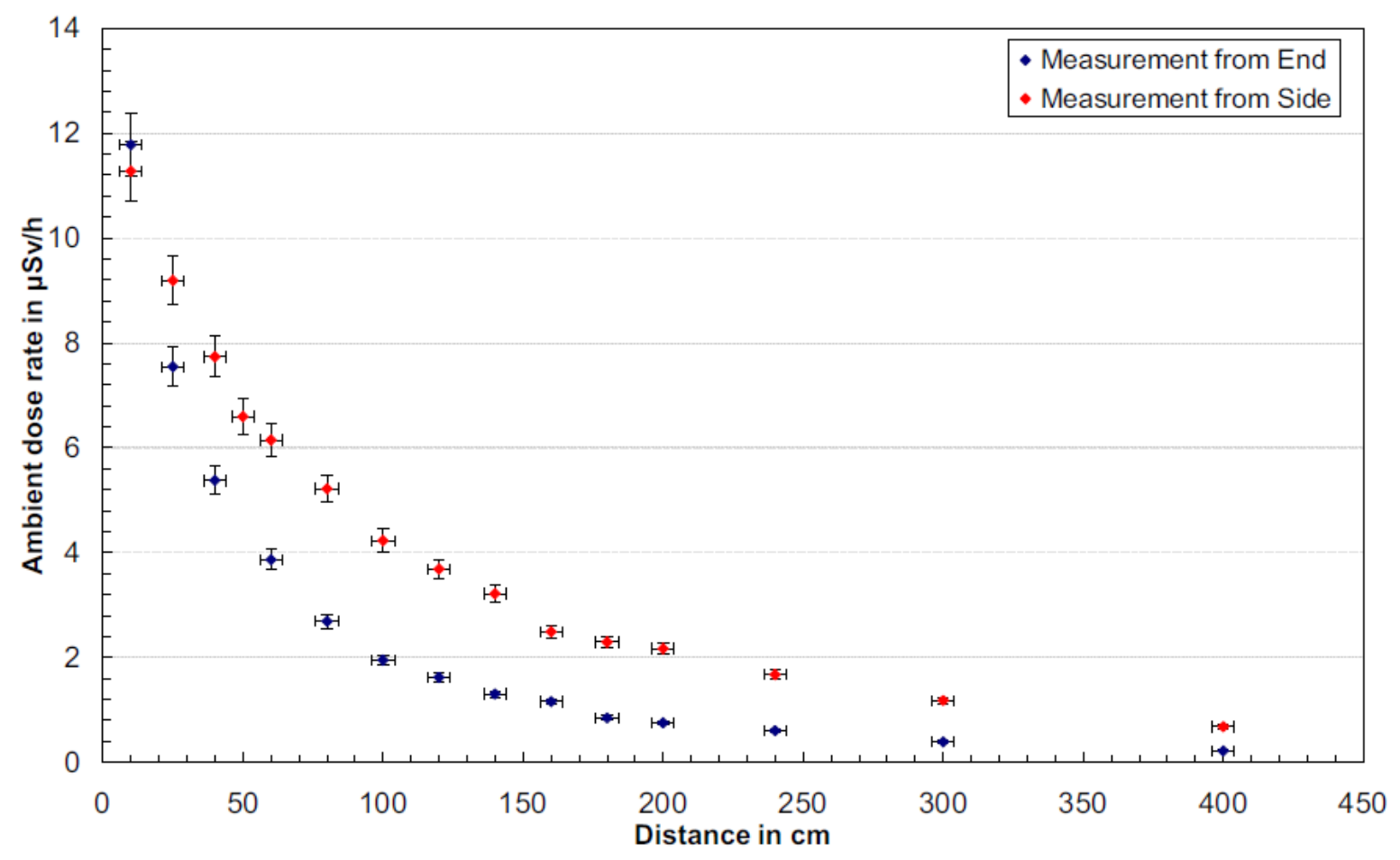

Figure 3: Gamma Dose Rate from $48 Y \mathrm{UF}_{6}$ cylinder 
The above figure has been reproduced from Figure 5.9 of the associated reference. ${ }^{14}$ In this case the background radiation of $0.123 \mu \mathrm{Sv} / \mathrm{hr}$ has already been subtracted. Blue markers are the measured values from the head end and red markers from the side of the cylinder. Error bars are provided by the relative standard deviation of the individual measurement points, which are below 5\% . Dose rate from the side of the cylinder is higher, because there is a larger area exposed to the detector. 


\subsection{References}

1. Inspection Activities Associated with Limited-Frequency Unannounced Access Model Applied to Gas Centrifuge Type Enrichment Plants, Inspectorates and Relevant Technology Holders, Hexapartite Safeguards Project, February 1983

2. IAEA. Implementation of the NPT Safeguards Agreement and Relevant Provisions of Security Council Resolutions in the Islamic Republic of Iran. GOV/2015/15 D13, International Atomic Energy Agency Board of Governors, February 19, 2015.

3. INMM. Peixoto, Orpet. "Safeguards at the Commercial Centrifuge Plant at Resende, Brazil." Proceedings of the Institute of Nuclear Materials Management INMM 50th Annual Meeting Tucson, AZ, July 12-16, 2009.

4. IAEA. Model Safeguards Approach for Gas Centrifuge Enrichment Plants. SG-OP-GNRL-GD003.16, International Atomic Energy Agency SGCP-PSS, June 8, 2006.

5. Yamashita, K., Miyamoto, F., Nakagawa, S. T. Tanaka, "Safeguards Approach for High Temperature Engineering Test Reactor (HTTR)", Proceedings of the Institute of Nuclear Materials Management INMM 37th Annual Meeting Naples, FL July 28-August 1, 1996.

6. Bytchkov, et al. Safeguards Aspects of the Conditioning and Transfer of Irradiated Fuel in a Fast Breeder Reactor in Kazakhstan. Proceedings of the Institute of Nuclear Materials Management INMM 41st Annual Meeting New Orleans, LA July 16-20, 2000.

7. IAEA. Safeguards Techniques and Equipment: 2011 Edition, International Atomic Energy Agency, Vienna, 2011.

8. Leicman, J. et al. "Design of a Safeguards System for Chernobyl Spent Fuel New Conditioning and Disposition Project." Proceedings of the Institute of Nuclear Materials Management INMM 43rd Annual Meeting Orlando, FL June 23-27, 2002.

9. Lucero, R. Glidewell, D. Bartberger, J., and Perlinski A. "Mobile Monitoring System for Container Transport (MMCT); MMCT Installation at the Chernobyl Nuclear Power Plant." Proceedings of the Institute of Nuclear Materials Management INMM 45th Annual Meeting Orlando, FL, July 18-22, 2004.

10. Pickett, C.A. A Continuous Automated Vault Inventory System (CAVIS) for Accountability Monitoring of Stored Nuclear Materials. Y-12, Y/DW-1351, December 8, 1994.

11. Wenz, T. and Menlove, H. "In Situ Pu Isotopic Measurements using Electromechanically Cooled HPGe Detectors at PFPF." Proceedings of the Institute of Nuclear Materials Management INMM 42nd Annual Meeting Indian Wells, CA July 15-19, 2001.

12. Abhold, M.E. "Design of the Improved Plutonium Canister Assay System (iPCAS)." Proceedings of the Institute of Nuclear Materials Management INMM 42nd Annual Meeting Indian Wells, CA July 15-19, 2001.

13. IAEA. Model Safeguards Approach for Gas Centrifuge Enrichment Plants. SG-OP-GNRL-GD-0003, International Atomic Energy Agency Department of Safeguards, June 8, 2006.

14. Meyering, A. Investigations of the Effective Dose Rate from $\mathrm{UF}_{6}$-cylinders by Monte-Carlo Simulations in respect of Radiation Protection by Andreas Meyering, Master thesis presented to the Department of Physics University of Münster, Münster March 2012 



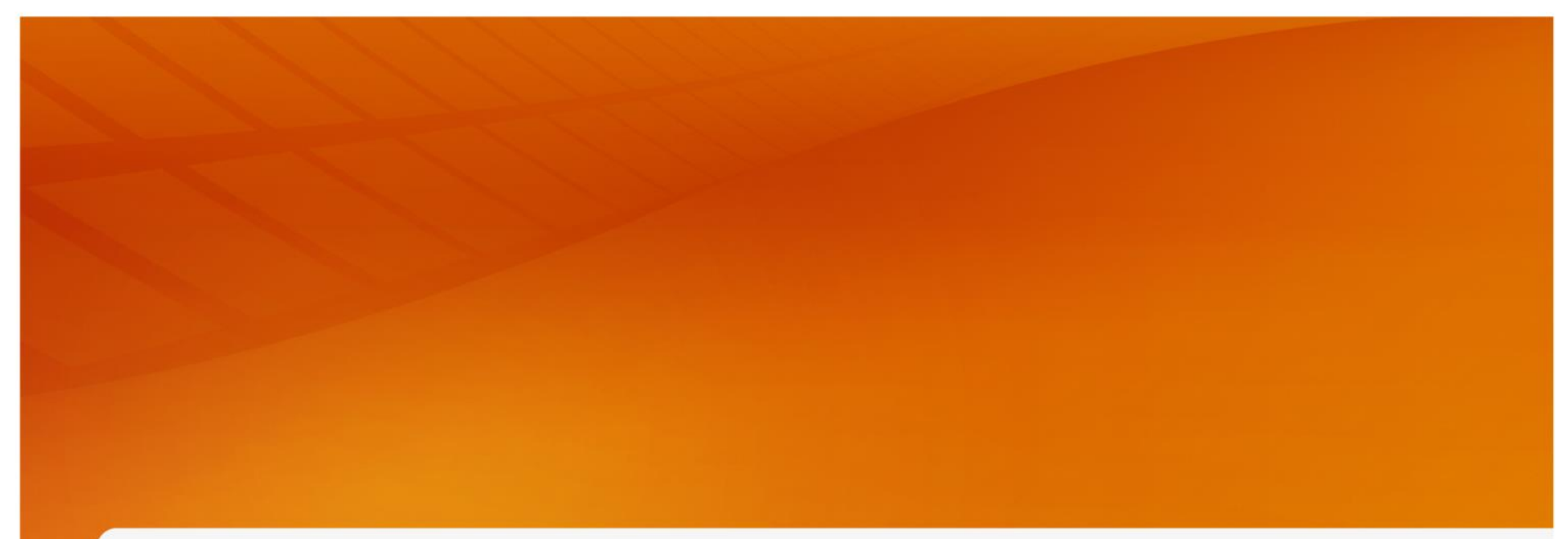

\section{Pacific Northwest}

NATIONAL LABORATORY

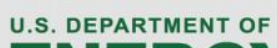
ENERGY

Proudly Operated by Battelle Since 1965

902 Battelle Boulevard

P.O. Box 999

Richland, WA 99352

1-888-375-PNNL (7665)

www.pnnl.gov

\section{OFFICIAL USE ONLY}

